\title{
VIABILIDADE ECONÔMICA DA PRODUÇÃO DE CARVÃO VEGETAL EM DOIS SISTEMAS PRODUTIVOS
}

\author{
Aylson Costa Oliveira ${ }^{1}$, Thiago Taglialegna Salles ${ }^{1}$, Bárbara Luísa Corradi Pereira ${ }^{2}$, \\ Angélica de Cássia Oliveira Carneiro ${ }^{3}$, Camila Soares Braga ${ }^{4}$, Rosemeire Cristina dos Santos ${ }^{5}$ \\ 1Eng. Florestal, Doutorando em Ciência Florestal, UFV, Viçosa, MG, Brasil - aylsoncosta@ gmail.com; thiagotsalles@gmail.com \\ ${ }^{2}$ Eng $^{\mathrm{a}}$. Florestal, Doutoranda em Ciência Florestal, UFV, Viçosa, MG, Brasil - babicorradi@ gmail.com \\ ${ }^{3}$ Eng $^{\mathrm{a}}$. Florestal, Depto. de Engenharia Florestal, UFV, Viçosa, MG, Brasil - cassiacarneiro1 @ gmail.com \\ ${ }^{4}$ Eng $^{\mathrm{a}}$. Florestal, M.Sc., Confederação da Agricultura e Pecuária do Brasil, Viçosa, MG, Brasil - bragaflorestal@gmail.com \\ ${ }^{5}$ Economista, M.Sc., Confederação da Agricultura e Pecuária do Brasil, Viçosa, MG, Brasil - rose1973@uol.com.br
}

Recebido para publicação: 23/05/2013 - Aceito para publicação: 19/11/2013

\begin{abstract}
O objetivo deste trabalho foi analisar a viabilidade econômica da produção de carvão vegetal em dois sistemas produtivos: oito fornos de superfície acoplados a uma fornalha para queima de gases e dez fornos do tipo "rabo-quente" sem sistema de queima de gases. Para análise econômica, definiu-se uma produção anual média igual a 1.571 metros cúbicos de carvão (mdc) e horizonte de planejamento de 12 anos, sendo propostos 2 cenários. No primeiro cenário, após a colheita da madeira, realiza-se o plantio de uma nova floresta, permanecendo o custo da madeira constante em todo o planejamento; no segundo cenário, após a colheita, considerou-se a condução da brotação, reduzindo os custos na $2^{\mathrm{a}}$ rotação e consequentemente os custos da madeira. A análise econômica foi realizada através da determinação dos seguintes indicadores: Valor Presente Líquido (VPL), Valor Anual Equivalente (VAE), Razão Benefício/Custo (B/C) e Lucratividade. Os indicadores calculados demonstraram a viabilidade dos dois sistemas produtivos avaliados em ambos os cenários propostos, porém o sistema fornos-fornalha apresentou melhores valores para os indicadores. Conclui-se que a produção de carvão vegetal nos sistemas avaliados foram viáveis economicamente, com o sistema fornos-fornalha gerando maior lucro ao produtor de carvão.
\end{abstract}

Resumo

Palavras-chave: Fornos de alvenaria; análise determinística; valor presente líquido.

\begin{abstract}
Economic viability of charcoal production in two production systems. The objective of this study was to analyze the economic viability of charcoal production in two conversion technologies: eight surface kilns coupled to a furnace for burning gases (kilns-furnace system) and ten "rabo-quente" or traditional charcoal kilns without burning gases system. An average annual production of 1571 cubic meters of charcoal (mdc) was used to perform the economic analysis. A planning horizon of 12 years and two scenarios were proposed. In the first scenario, after harvesting the wood, the planting of a new forest was performed, and the cost of wood remained constant throughout the planning horizon. In the second scenario, after the harvest, the conduction of shooting was considered, which reduced costs in the second rotation and consequently the cost of wood. The economic analysis was performed by determining the following indicators: Net Present Value (NPV), Equivalent Annual Value (EAV) and Benefit - Cost Reason $(\mathrm{B} / \mathrm{C})$. Calculated indicators demonstrated the viability of producing charcoal in the two production systems in both scenarios proposed, but kilns-furnace system presented better values. As conclusion, production of charcoal in the evaluated systems were economically viable. Kilns-furnace system was able to generate more profit to charcoal producer.

Keywords: Kilns; deterministic analysis; net present value.
\end{abstract}

\section{INTRODUÇÃO}

O Brasil é o único país que produz carvão vegetal em larga escala para ser utilizado na indústria, destacando-se, então, como maior produtor e consumidor de carvão vegetal. Ressalte-se que o consumo do carvão vegetal está basicamente concentrado no mercado interno. Os principais destinos são os setores de ferro-gusa e aço, que consomem $72 \%$ do carvão vegetal produzido, e de ferro-liga, que utiliza $12 \%$, 
seguidos do residencial (cocção e aquecimento residencial), do industrial (excluindo-se a siderurgia), com destaque para produção de cimentos, indústria química, de alimentos e de cerâmicas (EMPRESA DE PESQUISA ENERGÉTICA (EPE), 2011).

A maior parte da produção brasileira de carvão é realizada em fornos de alvenaria, do tipo "raboquente", e fornos de superfície, em que o controle da carbonização baseia-se em fatores subjetivos, tais como coloração da fumaça e temperatura externa do forno sentida pelo tato das mãos (ARRUDA et al., 2011). Nesses tipos de fornos, há grande dificuldade no controle das emissões de gases poluentes, afetando toda a unidade de produção e áreas vizinhas.

Atualmente, estudos estão sendo realizados visando o desenvolvimento de fornalhas a serem acopladas aos fornos de alvenaria para combustão dos gases poluentes gerados durante a carbonização da madeira (CARDOSO et al., 2010; OLIVEIRA et al., 2013). Esses estudos verificaram a viabilidade técnica e ambiental dessa tecnologia, como o aumento no rendimento em carvão vegetal e melhoria de suas propriedades, além da eliminação quase total da emissão de gases poluentes.

No entanto, para a efetiva disseminação e adoção dessas novas tecnologias no processo de carbonização por parte dos pequenos e médios produtores de carvão vegetal, além dos aspectos técnicos e ambientais, a utilização de fornalhas acopladas aos fornos deve ser economicamente viável.

A análise econômica de um investimento envolve o uso de técnicas e critérios de análise que comparam os custos e as receitas inerentes ao projeto, visando decidir se ele deve ou não ser implementado (REZENDE; OLIVEIRA, 2008).

Num projeto em que a produção de carvão vegetal tem como matéria-prima a madeira vinda de plantios florestais, a questão econômica deve levar em conta não só os aspectos técnicos da tecnologia de conversão, mas os diferentes manejos silviculturais que o produtor possa adotar. Um exemplo seria a condução da brotação das cepas no lugar da reforma do povoamento após a colheita. Dessa forma, a análise econômica realizada quando se deseja investir em determinada tecnologia se torna mais robusta, trazendo um número maior de cenários disponíveis para a escolha, pelo investidor, daquele que apresentar maior rentabilidade.

O objetivo deste trabalho foi analisar a viabilidade econômica da produção de carvão vegetal a partir de plantios de eucalipto, com e sem condução de brotação, e em dois sistemas produtivos: fornos de superfície acoplados à fornalha para queima de gases (sistema fornos-fornalha) e fornos do tipo "raboquente" sem sistema de queima de gases.

\section{MATERIAL E MÉTODOS}

O estudo baseou-se na simulação de projetos com fins de produção de carvão vegetal em Minas Gerais, com valores de produtividade, custos e receitas referentes ao ano de 2013. Para realização da análise econômica da produção de carvão vegetal, foram propostos dois cenários.

Para o cenário 1, considerou-se que o produtor possui a área de plantio de eucalipto em idade de corte (6 anos) e, após a colheita do volume de madeira necessário à produção de carvão, é realizado o plantio de uma nova floresta. Para a reforma da floresta, há novamente todos os custos envolvidos na implantação: custos com muda, preparo do solo, adubação etc.

Já no cenário 2, a situação inicial é a mesma, mas após a colheita é feita a condução de brotação das cepas remanescentes do povoamento. Dessa forma, os custos da $2^{a}$ rotação são menores, pois não há compra de mudas e preparo do solo, além de menor gasto com fertilizantes e outros insumos, proporcionando menor custo da madeira.

Foram definidos dois sistemas produtivos de carvão vegetal: um conjunto de fornos acoplado a uma fornalha, definido como sistema fornos-fornalha; e um conjunto de fornos "rabo-quente".

O forno do tipo "rabo-quente" é um forno simples, de alvenaria, normalmente com forma semiesférica. Ao longo de toda a extensão de sua parede são deixados orifícios para a entrada de ar e saída dos gases gerados. O progresso da carbonização é avaliado pela coloração dos gases liberados através dos orifícios, e o controle ocorre pelo fechamento progressivo das entradas de ar. O controle subjetivo da carbonização impossibilita o controle adequado da temperatura interna do forno, prejudicando a qualidade do carvão vegetal e elevando a produção de madeira semicarbonizada.

O forno do sistema fornos-fornalha é de base circular, com paredes verticais e copa semiesférica. É um forno de superfície, de alvenaria, e dotado de seis controladores de ar (câmaras de admissão) na sua 
base. A fornalha adaptada aos fornos é composta por um sistema de alimentação dos gases (situado na parte posterior dos fornos), câmara de combustão, sistema de admissão de ar primário e chaminé. O acompanhamento da carbonização é feito por meio de medições da temperatura em cilindros metálicos instalados nas paredes dos fornos, monitorados com o uso de pirômetro infravermelho. Para esse fim, também é feita a inspeção visual das aberturas para entrada de oxigênio, por onde o controle da temperatura é realizado.

Os queimadores ou fornalhas acoplados aos fornos de carbonização têm o objetivo de incinerar os gases gerados durante o processo, transformando a poluição em energia na forma de calor. A fornalha é abastecida com material lignocelulósico e é acesa após a ignição dos fornos. Abastecimentos posteriores são necessários para manter a chama acesa e elevar a temperatura na fornalha. Quando os gases gerados durante a carbonização no forno atingem $\pm 120^{\circ} \mathrm{C}$, o abastecimento da fornalha é suspenso, pois os gases são capazes de manter a combustão. Desse momento até próximo ao fim da carbonização, a chama dentro da câmara de combustão da fornalha permanece acesa. O presente estudo não considerou $o$ aproveitamento da energia resultante da queima dos gases. A produção média mensal normalmente alcançada por pequenos e/ou médios produtores no Estado é de 131 metros cúbicos de carvão (mdc), correspondendo a $1.571 \mathrm{mdc}$ anualmente. Esse valor foi adotado como ponto de partida para dimensionamento dos projetos.

Para o cálculo do número de fornos a serem utilizados nos projetos, partiu-se de resultados do estudo de Oliveira et al. (2013), que encontraram um rendimento gravimétrico médio para carbonizações nos sistemas fornos-fornalha de $32 \%$. Esses mesmos autores citam que o rendimento gravimétrico médio de fornos do tipo "rabo-quente" é igual a $25 \%$. Considerou-se um fator de conversão de estéreo de lenha (st) para $\mathrm{m}^{3}$ igual a 0,7 , densidade média da madeira a ser carbonizada igual a $450 \mathrm{~kg} / \mathrm{m}^{3} \mathrm{e}$ densidade média do carvão produzido igual a $220 \mathrm{~kg} / \mathrm{m}^{3}$. Tendo em vista que cada forno tem potencial para três carbonizações por mês, são necessários oito fornos do sistema fornos-fornalha, ou dez fornos "rabo-quente", com capacidade de 12 st de lenha, para se atingir uma produção anual próxima à definida inicialmente.

Os custos de construção dos fornos e sua vida útil foram extraídos do estudo de Oliveira (2012). O custo de construção de sistemas fornos-fornalha, incluindo os fornos, dutos, fornalha e chaminé, foram iguais a $\mathrm{R} \$ 8.295,70$, enquanto os fornos "rabo-quente" tiveram custo de construção igual a $\mathrm{R} \$ 5.700,00$. Os fornos "rabo-quente" são mais baratos em consequência do menor número de tijolos utilizados, além de não haver construção de dutos, fornalha e chaminé. Foi considerada uma vida útil do sistema fornosfornalha de 6 anos, enquanto dos fornos "rabo-quente" foi de 2 anos.

Para a elaboração do fluxo de caixa de cada sistema produtivo, considerou-se $\mathrm{R} \$ 35,18$ como o custo do estéreo (st) de madeira ao longo de todo o horizonte de planejamento do cenário 1 . Para o cenário 2, o custo de $\mathrm{R} \$ 35,18 /$ st foi considerado para os 6 anos iniciais, enquanto que para os demais (712 anos) o custo da madeira seria de $\mathrm{R} \$ 21,00 /$ st. Esses valores foram determinados segundo dados da Associação das Siderúrgicas para Fomento Florestal (ASIFLOR, 2013).

Para abastecimento da fornalha, foi considerado o consumo de $100 \mathrm{~kg}$ de madeira por carbonização em cada forno. Logo, a fornalha consome $800 \mathrm{~kg}$ de madeira para cada ciclo de carbonização nos oito fornos, o equivalente a 2,54 st.

O valor de venda do carvão vegetal foi igual a $\mathrm{R} \$ 110,00$ por mdc, preço médio para o estado de Minas Gerais em fevereiro de 2013 (CIFLORESTAS, 2013).

Nos anos em que não houve construção dos fornos, foi considerado um custo de manutenção igual a $5 \%$ sobre o valor total gasto na sua construção, sendo, portanto, igual a $\mathrm{R} \$ 414,79$ para o sistema fornos-fornalha e de R \$285,00 para os fornos "rabo-quente".

Para os cenários avaliados, em ambos os tipos de fornos utilizados, considerou-se a necessidade de contratação de mão de obra para auxiliar o produtor nas atividades de carbonização, no valor de $\mathrm{R} \$ 1.322,10$ por mês (salário mínimo de $\mathrm{R} \$ 678,00$, somado aos encargos sociais - $95 \%$ ).

\section{Análise econômica e financeira}

Foi considerado um horizonte de planejamento de 12 anos, contemplando dois cortes de madeira de eucalipto aos 6 anos. A taxa de juros empregada foi de 7,5\% ao ano.

A análise econômica foi realizada através da determinação dos seguintes indicadores: Valor Presente Líquido (VPL), Valor Anual Equivalente (VAE), Razão Benefício/Custo (B/C) e Lucratividade. 
O VPL é definido como a diferença positiva entre receitas e custos, atualizados para uma determinada taxa de desconto. Para um projeto ser viável, o valor encontrado para esse critério deve ser maior que zero (REZENDE; OLIVEIRA, 2008).

$$
\mathrm{VPL}=\sum_{j=0}^{n} R_{j}(1+i)^{-j}-\sum_{j=0}^{n} C_{j}(1+i)^{-j}
$$

Em que: $R j=$ receitas no período $j$, em $\mathrm{R} \$$;

$C j=$ custos no período $j$, em R $\$$

$i=$ taxa de desconto (\% ao ano);

$j$ = período de ocorrência de $R j$ e $C j$, ano;

$n=$ duração do projeto, em anos.

O VAE é uma parcela periódica e constante que paga o VPL da opção de investimento em análise ao longo do horizonte de planejamento. O VAE transforma o valor atual do projeto em um fluxo de receitas ou custos periódicos e contínuos. Valores positivos para esse critério indicam a viabilidade do projeto, sendo que o projeto é tanto mais viável quanto maior for o VAE (REZENDE; OLIVEIRA, 2008).Com o período de capitalização anual, a fórmula de cálculo fica igual a:

$$
\mathrm{VAE}=\frac{\mathrm{VPL}(i)}{\left[1-(1+i)^{-n}\right]}
$$

Em que: $\mathrm{VPL}=$ valor presente líquido, em $\mathrm{R} \$ ; n=$ duração do projeto, em anos; $i=$ taxa de desconto (\% ao ano).

A razão benefício-custo (B/C) é obtida pela razão entre o valor presente dos benefícios e o valor presente dos custos para uma dada taxa de desconto. A viabilidade do projeto é verificada quando o resultado é maior que 1 (REZENDE; OLIVEIRA, 2008).

$$
\mathrm{B} / \mathrm{C}=\frac{\sum_{j=0}^{n} R_{j}(1+i)^{-j}}{\sum_{j=0}^{n} C_{j}(1+i)^{-j}}
$$

Em que: $R j=$ receita no final do ano $j$, em $\mathrm{R} \$$;

$C j=$ custo no final do ano $j$ em R $\$$

$i=$ taxa de desconto (\% ao ano);

$n=$ duração do projeto, em anos.

A lucratividade é um indicador que demonstra a eficiência operacional de um negócio. É expressa como um valor percentual que indica a proporção de ganhos de um negócio (REZENDE; OLIVEIRA, 2008).

Para a análise financeira, o indicador estimado foi a lucratividade:

$$
\text { Lucratividade }=\frac{\text { Lucro Líquido }}{\text { Receita Total }} \times 100
$$

Em que: Lucro Líquido e Receita Total, em R\$.

\section{RESULTADOS E DISCUSSÃO}

\section{Cenário 1}

Na tabela 1 são apresentados os custos anuais relativos ao consumo da madeira e as receitas anuais geradas pela comercialização do carvão vegetal, no sistema fornos-fornalha e nos fornos "raboquente", segundo as condições previstas no Cenário 1. 
Para uma produção anual de 1571 mdc, os fornos "rabo-quente" apresentaram consumo anual de 4.320 st de madeira, enquanto o sistema fornos-fornalha teve um consumo de 3.547 st. Observa-se na tabela 1 que, para uma mesma produção de carvão vegetal e, portanto, uma mesma receita, os fornos "rabo-quente" apresentaram custo com a madeira 21,8\% maior que o sistema fornos-fornalha. Isso se deve à diferença no rendimento gravimétrico, 25\% para o "rabo-quente" contra 32\% para o sistema fornos-fornalha, acarretando maior consumo de madeira.

Tabela 1. Custos anuais com madeira e receitas anuais do carvão vegetal, Cenário 1.

Table1. Annual costs with wood and annual revenues with charcoal, Scenario 1.

\begin{tabular}{|c|c|c|c|c|c|c|}
\hline $\begin{array}{l}\text { Sistemas } \\
\text { de fornos }\end{array}$ & $\begin{array}{c}\text { Carbonizações } \\
\text { no ano }\end{array}$ & $\begin{array}{c}\text { Consumo } \\
\text { de madeira } \\
(\mathbf{s t})^{(2)}\end{array}$ & $\begin{array}{c}\text { Custo da } \\
\text { madeira } \\
(\mathbf{R} \$)^{(3)}\end{array}$ & $\begin{array}{c}\text { Custo médio } \\
\text { por } \\
\text { carbonização }\end{array}$ & $\begin{array}{c}\text { Produção } \\
\text { de carvão } \\
\text { (mdc) }\end{array}$ & $\begin{array}{c}\text { Receita do } \\
\text { carvão (R\$) }\end{array}$ \\
\hline $\begin{array}{l}\text { Fornos- } \\
\text { fornalha }\end{array}$ & 288 & 3.547 & $124.798,54$ & 433,33 & 1.571 & $172.800,00$ \\
\hline $\begin{array}{l}\text { "Rabo- } \\
\text { quente" }\end{array}$ & 360 & 4.320 & $151.977,60$ & 422,16 & 1.571 & $172.800,00$ \\
\hline
\end{tabular}

O fluxo de caixa do Cenário 1 (Tabela 2) foi elaborado de acordo com os custos e receitas determinados para a produção de carvão vegetal no sistema fornos-fornalha e nos fornos "rabo-quente".

Tabela 2. Fluxo de caixa do Cenário 1.

Table 2. Cash flow of Scenario 1.

\begin{tabular}{lcccccc}
\hline \multirow{2}{*}{ Ano } & \multicolumn{3}{c}{ Sistema fornos-fornalha } & \multicolumn{3}{c}{ Fornos "rabo-quente" } \\
\cline { 2 - 7 } & Custo & Receita & Saldo & Custo & Receita & Saldo \\
\hline 1 & $148.959,64$ & $172.800,00$ & $23.840,36$ & $173.542,80$ & $172.800,00$ & $-742,80$ \\
2 & $141.078,72$ & $172.800,00$ & $31.721,28$ & $168.127,80$ & $172.800,00$ & $4.672,20$ \\
3 & $141.078,72$ & $172.800,00$ & $31.721,28$ & $173.542,80$ & $172.800,00$ & $-742,80$ \\
4 & $141.078,72$ & $172.800,00$ & $31.721,28$ & $168.127,80$ & $172.800,00$ & $4.672,20$ \\
5 & $141.078,72$ & $172.800,00$ & $31.721,28$ & $173.542,80$ & $172.800,00$ & $-742,80$ \\
6 & $141.078,72$ & $172.800,00$ & $31.721,28$ & $168.127,80$ & $172.800,00$ & $4.672,20$ \\
7 & $148.959,64$ & $172.800,00$ & $23.840,36$ & $173.542,80$ & $172.800,00$ & $-742,80$ \\
8 & $141.078,72$ & $172.800,00$ & $31.721,28$ & $168.127,80$ & $172.800,00$ & $4.672,20$ \\
9 & $141.078,72$ & $172.800,00$ & $31.721,28$ & $173.542,80$ & $172.800,00$ & $-742,80$ \\
10 & $141.078,72$ & $172.800,00$ & $31.721,28$ & $168.127,80$ & $172.800,00$ & $4.672,20$ \\
11 & $141.078,72$ & $172.800,00$ & $31.721,28$ & $173.542,80$ & $172.800,00$ & $-742,80$ \\
12 & $141.078,72$ & $172.800,00$ & $31.721,28$ & $168.127,80$ & $172.800,00$ & $4.672,20$ \\
\hline Total & $1.708 .706,49$ & $2.073 .600,00$ & $364.893,51$ & $2.050 .023,60$ & $2.073 .600,00$ & $23.576,40$ \\
\hline
\end{tabular}

Conforme observado na tabela 2, para o sistema fornos-fornalha, em todos os anos do horizonte de planejamento, o saldo anual foi sempre positivo, com menor valor igual a R\$23.840,36 nos anos 1 e 7 , devido aos maiores custos relativos à construção dos fornos, dutos, fornalha e chaminé. Para os fornos "rabo-quente", nos anos em que é necessária a construção dos fornos $(1,3,5,7,9$ e 11), observou-se um saldo negativo igual a R \$ -742,80, tornando a produção de carvão inviável economicamente nesses anos. Nos demais anos, quando se realiza somente a manutenção dos fornos, o saldo torna-se positivo, com valor igual a $\mathrm{R} \$ 4.672,20$ por ano.

Normalmente, os produtores desconsideram diversos custos envolvidos, acreditando, então, que a atividade está gerando lucro (saldo positivo) mesmo nos anos em que a tabela 2 mostra prejuízo. Colombo et al. (2006) comprovam tal fato, comentando que os gastos não considerados podem ser a mão de obra para a construção dos fornos, a utilização de veículo próprio nas operações de transporte de lenha, a aquisição da argila na construção dos fornos ou o emprego de membros da própria família no processo produtivo, com baixa remuneração. Esses procedimentos, quando praticados, camuflam os custos reais de produção.

Na tabela 3 são apresentados os indicadores econômicos, Valor Presente Líquido (VPL), Valor Anual Equivalente (VAE), Razão Benefício-Custo (B/C) e indicador financeiro, Lucratividade, para o Cenário 1. 
O Valor Presente Líquido (VPL) para ambos os tipos de fornos avaliados foi positivo, indicando a viabilidade econômica dos projetos. Porém o VPL obtido para o sistema fornos-fornalha foi igual a $\mathrm{R} \$ 233.291,57$, e para os fornos "rabo-quente" o valor encontrado foi igual a $\mathrm{R} \$ 14.440,52$, valor muito inferior ao verificado para o sistema fornos-fornalha.

Tabela 3. Indicadores econômicos e financeiro do Cenário 1.

Table 3. Economic indicators and financial indicator of Scenario 1.

\begin{tabular}{lcc}
\hline Indicador & $\begin{array}{c}\text { Sistema } \\
\text { fornos-fornalha }\end{array}$ & Fornos "rabo-quente" \\
\hline VPL (R\$) & $233.291,57$ & $14.440,52$ \\
VAE (R\$/ano) & $30.159,43$ & $1.866,84$ \\
B/C & 1,21 & 1,01 \\
Lucratividade $(\%)$ & $17,5 \%$ & $1,1 \%$ \\
\hline
\end{tabular}

O Valor Anual Equivalente (VAE) representa o retorno financeiro anual e foi positivo para os dois projetos analisados, indicando, juntamente com o VPL, a viabilidade de ambos.

Para o sistema fornos-fornalha o VAE foi igual a $\mathrm{R} \$ 30.159,43$, o que equivale a $\mathrm{R} \$ 2.513,26$ por mês (3,7 salários-mínimos referentes ao ano de 2013). Esse valor representa o valor recebido pelo produtor rural, que, mesmo contratando um ajudante, tem que exercer diversas atividades relacionadas com a produção de carvão vegetal.

Para os fornos "rabo-quente", o VAE foi igual a $\mathrm{R} \$ 1.866,84$, com equivalente mensal de $\mathrm{R} \$ 155,57$ (0,2 salários mínimos), ou seja, o valor recebido mensalmente pelo produtor rural é inferior ao valor pago à mão de obra $(\mathrm{R} \$ 678,00)$. É por essa razão que normalmente os produtores de carvão não cumprem as exigências trabalhistas vigentes, como, por exemplo, não contratar mão de obra com carteira assinada.

Ambas as razões Benefício-Custo (B/C) foram superiores a 1. Para o sistema fornos-fornalha, a razão B/C foi de 1,21, e para os fornos "rabo-quente" essa razão foi igual a 1,01. Dessa forma, para o sistema fornos-fornalha, as receitas superam os custos em $21 \%$. Para os fornos "rabo-quente", as receitas superaram em apenas $1 \%$ os custos envolvidos na produção de carvão vegetal, sendo, portanto, menos rentáveis.

A lucratividade do sistema fornos-fornalha foi de $17,5 \%$ ao ano, ou seja, para cada $R \$ 100,00$ comercializados de carvão vegetal, o produtor terá como lucro R\$ 17,50. Para os fornos "rabo-quente", a lucratividade calculada foi igual a $1,1 \%$, significando um lucro de apenas $R \$ 1,10$ em cada $R \$ 100,00$ de carvão comercializado.

Nas condições apresentadas para o Cenário 1, os indicadores econômicos indicam a viabilidade dos projetos. No entanto, a produção de carvão vegetal em fornos "rabo-quente" produziu lucro significativamente baixo, quase que inviável economicamente, enquanto que os valores encontrados para o sistema fornos-fornalha foram satisfatórios. Castro et al. (2007), avaliando a viabilidade econômica da produção de carvão vegetal a partir de florestas plantadas, observou uma probabilidade de $12 \%$ de os indicadores econômicos para projetos desse porte serem negativos, tornando os projetos inviáveis se os custos estiverem muito elevados e/ou os preços e produção estiverem em níveis baixos.

\section{Cenário 2}

$\mathrm{Na}$ tabela 4 são apresentados os custos anuais referentes ao consumo da madeira e as receitas anuais geradas pela comercialização do carvão vegetal, no sistema fornos-fornalha e nos fornos "raboquente", segundo as condições do Cenário 2.

Tabela 4. Custos anuais com madeira e receitas anuais do carvão vegetal, Cenário 2.

Table 4. Annual costs with wood and annual revenues with charcoal, Scenario 2.

\begin{tabular}{|c|c|c|c|c|c|c|c|}
\hline $\begin{array}{l}\text { Sistemas } \\
\text { de fornos }\end{array}$ & $\begin{array}{c}\text { Carbonizações } \\
\text { no ano }\end{array}$ & $\begin{array}{c}\text { Período } \\
\text { (anos) }\end{array}$ & $\begin{array}{l}\text { Consumo } \\
\text { de madeira } \\
(\mathrm{st})^{(2)}\end{array}$ & $\begin{array}{c}\text { Custo da } \\
\text { madeira } \\
(\mathbf{R} \$)^{(3)}\end{array}$ & $\begin{array}{c}\text { Custo médio } \\
\text { por } \\
\text { carbonização }\end{array}$ & $\begin{array}{c}\text { Produção } \\
\text { de carvão } \\
\text { (mdc) }\end{array}$ & $\begin{array}{c}\text { Receita do } \\
\text { carvão (R\$) }\end{array}$ \\
\hline $\begin{array}{l}\text { Fornos- } \\
\text { fornalha }\end{array}$ & 288 & $\begin{array}{l}1-6 \\
7-12\end{array}$ & 3.547 & $\begin{array}{r}124.798,54 \\
74.496,00\end{array}$ & $\begin{array}{l}433,33 \\
258,67\end{array}$ & 1.571 & $172.800,00$ \\
\hline $\begin{array}{l}\text { "Rabo- } \\
\text { quente" }\end{array}$ & 360 & $\begin{array}{l}1-6 \\
7-12\end{array}$ & 4.320 & $\begin{array}{r}151.977,60 \\
90.720,00\end{array}$ & $\begin{array}{l}422,16 \\
252,00\end{array}$ & 1.571 & $172.800,00$ \\
\hline
\end{tabular}

(1) Considerando-se 3 carbonizações mensais por forno. ${ }^{(2)}$ Madeira carbonizada somada à madeira queimada na fornalha para 0 sistema fornos-fornalha. ${ }^{(3)}$ Custo da madeira igual a $\mathrm{R} \$ 35,18 / \mathrm{st}$ nos anos 1 a 6 e R\$21,00/st nos anos 7 a 12. 
Para o Cenário 2, o produtor realiza a condução da brotação de eucalipto após o primeiro corte aos 6 anos. Dessa forma, a partir do $7^{\circ}$ ano os custos com madeira dos projetos são reduzidos em $40 \%$, passando de R\$ 124.798,54/ano para R\$ 74.496,00/ano para o sistema fornos-fornalha; e de $\mathrm{R} \$ 151.977,60 /$ ano para $\mathrm{R} \$ 90.720,00 /$ ano para os fornos "rabo-quente". A produção, assim como o preço de comercialização do carvão vegetal, permaneceu constante em todo o período avaliado.

O fluxo de caixa do Cenário 2 (Tabela 5) foi elaborado de acordo com os custos e receitas determinados para a produção de carvão vegetal no sistema fornos-fornalha e nos fornos "rabo-quente", considerando as condições do Cenário 2.

Tabela 5. Fluxo de caixa do Cenário 2.

Table 5. Cash flow of Scenario 2.

\begin{tabular}{|c|c|c|c|c|c|c|}
\hline \multirow{2}{*}{ Ano } & \multicolumn{3}{|c|}{ Sistema fornos-fornalha } & \multicolumn{3}{|c|}{ Fornos "rabo-quente" } \\
\hline & Custo & Receita & Saldo & Custo & Receita & Saldo \\
\hline 1 & $148.967,17$ & $172.800,00$ & $23.832,83$ & $173.552,21$ & $172.800,00$ & $-752,21$ \\
\hline 2 & $141.086,25$ & $172.800,00$ & $31.713,75$ & $168.137,21$ & $172.800,00$ & $4.662,79$ \\
\hline 3 & $141.086,25$ & $172.800,00$ & $31.713,75$ & $173.552,21$ & $172.800,00$ & $-752,21$ \\
\hline 4 & $141.086,25$ & $172.800,00$ & $31.713,75$ & $168.137,21$ & $172.800,00$ & $4.662,79$ \\
\hline 5 & $141.086,25$ & $172.800,00$ & $31.713,75$ & $173.552,21$ & $172.800,00$ & $-752,21$ \\
\hline 6 & $141.086,25$ & $172.800,00$ & $31.713,75$ & $168.137,21$ & $172.800,00$ & $4.662,79$ \\
\hline 7 & $98.649,11$ & $172.800,00$ & $74.150,89$ & $112.275,72$ & $172.800,00$ & $60.524,28$ \\
\hline 8 & $90.768,20$ & $172.800,00$ & $82.031,80$ & $106.860,72$ & $172.800,00$ & $65.939,28$ \\
\hline 9 & $90.768,20$ & $172.800,00$ & $82.031,80$ & $112.275,72$ & $172.800,00$ & $60.524,28$ \\
\hline 10 & $90.768,20$ & $172.800,00$ & $82.031,80$ & $106.860,72$ & $172.800,00$ & $65.939,28$ \\
\hline 11 & $90.768,20$ & $172.800,00$ & $82.031,80$ & $112.275,72$ & $172.800,00$ & $60.524,28$ \\
\hline 12 & $90.768,20$ & $172.800,00$ & $82.031,80$ & $106.860,72$ & $172.800,00$ & $65.939,28$ \\
\hline Total & $1.406 .888,55$ & $2.073 .600,00$ & $666.711,45$ & $1.682 .477,60$ & $2.073 .600,00$ & $391.122,40$ \\
\hline
\end{tabular}

Devido à redução dos custos da madeira (Tabela 4), o saldo anual, conforme observado no fluxo de caixa para o Cenário 2 (Tabela 5), a partir do $7^{\circ}$ ano elevou-se para os dois projetos analisados. Para os fornos "rabo-quente", esse aumento foi significativo, passando do valor negativo de R \$ -752,21 para $\mathrm{R} \$ 60.524,28$ nos anos em que há necessidade de construção dos fornos, além dos custos com madeira e mão de obra. Para os anos em que os custos envolvem a manutenção dos fornos, madeira e mão de obra, o saldo passou de $\mathrm{R} \$$ 4.662,79/ano para $\mathrm{R} \$$ 65.939,28/ano.

Para o sistema fornos-fornalha, a redução do custo da madeira promoveu o aumento no saldo em mais de duas vezes, passando de $\mathrm{R} \$ 23.832,83$ para $\mathrm{R} \$ 74.150,89$ nos anos em que se deve realizar a construção de todo o sistema (fornos, dutos, fornalha e chaminé). Nos demais anos, o saldo elevou-se de $\mathrm{R} \$ 31.713,75$ para $\mathrm{R} \$ 82.031,80$.

Analisando o saldo total de cada projeto, verifica-se que, para o sistema fornos-fornalha, o saldo, que era igual a $\mathrm{R} \$ 364.893,51$ no Cenário 1 elevou-se para $\mathrm{R} \$ 666.711,45$ no Cenário 2, o que representa um aumento de $82,7 \%$. Para os fornos "rabo-quente", o saldo, que era de R $\$ 23.576,40$, teve um aumento de mais de 15 vezes, passando para o valor total de $\mathrm{R} \$ 391.122,40$ no Cenário 2.

Na tabela 6 são apresentados os indicadores econômicos Valor Presente Líquido (VPL), Valor Anual Equivalente (VAE) e Razão Benefício-Custo (B/C) e o indicador financeiro, Lucratividade, para o Cenário 2.

Tabela 6. Indicadores econômicos e financeiro do Cenário 2.

Table 6. Economic indicators and financial indicator of Scenario 2.

\begin{tabular}{lcc}
\hline Indicador & $\begin{array}{c}\text { Sistema } \\
\text { fornos-fornalha }\end{array}$ & Fornos "rabo-quente" \\
\hline VPL (R\$) & $386.272,24$ & $200.735,98$ \\
VAE (R\$/ano) & $49.936,44$ & $25.950,71$ \\
B/C & 1,41 & 1,18 \\
Lucratividade $(\%)$ & $28,9 \%$ & $15,0 \%$ \\
\hline
\end{tabular}


De acordo com as condições estabelecidas no Cenário 2, os indicadores econômicos e financeiros calculados demostraram a viabilidade econômica dos fornos "rabo-quente" e do sistema fornos-fornalha para produção anual de carvão vegetal de $1.571 \mathrm{mdc}$.

Os indicadores VPL, VAE e Lucratividade do sistema fornos-fornalha foram superiores em duas vezes aos verificados para os fornos "rabo-quente", conforme apresentado na tabela 6.

Quando o retorno anual encontrado (VAE) foi transformado para valores mensais, o valor encontrado para o sistema fornos-fornalha foi igual a $\mathrm{R} \$ 4.161,37$, e para os fornos "rabo-quente", o valor foi de $\mathrm{R} \$ 2.160,89$. Esses valores representam o valor mensal recebido pelo produtor de carvão, correspondendo a 6,1 salários mínimos para o sistema fornos-fornalha e 3,2 salários para os fornos "raboquente".

$\mathrm{O} \mathrm{B} / \mathrm{C}$ do sistema fornos-fornalha foi igual a 1,41, enquanto que para o "rabo-quente" esse valor foi igual a $1,18, \log$, o benefício gerado nos fornos "rabo-quente" é $16 \%$ menor se comparado com o benefício obtido na produção de carvão através do sistema fornos-fornalha.

De acordo com os valores percentuais obtidos para a lucratividade (Tabela 6), para cada $\mathrm{R} \$ 100,00$ de carvão vegetal comercializados, o produtor obterá lucro igual a $\mathrm{R} \$ 15,00$ produzindo nos fornos "rabo-quente"; no sistema fornos-fornalha, o lucro seria de $\mathrm{R} \$ 28,90$.

Os indicadores econômicos e financeiros calculados para o Cenário 2 (Tabela 6) foram superiores se comparados aos encontrados para as condições estabelecidas no Cenário 1 (Tabela 3). Esse fato deve-se à redução dos custos com madeira do $7^{\circ}$ ao $12^{\circ}$ ano, que promoveu a redução dos custos e o aumento do saldo anual em ambos os fornos avaliados, demonstrando que a condução da brotação dos plantios de eucalipto melhora a viabilidade econômica dos projetos analisados.

No Cenário 2, a produção de carvão vegetal em fornos "rabo-quente" torna-se mais atrativa do ponto de vista econômico. No entanto, o sistema fornos-fornalha apresentou viabilidade econômica superior, necessitando de uma menor quantidade de madeira para a produção de carvão. Dallastra (2010) comparou os sistemas de fornos do tipo container, retangular e cilíndrico com o sistema "rabo-quente", e também constatou que este último foi o de menor desempenho econômico. Além disso, outro ponto a favor da utilização do sistema fornos-fornalha é que a combustão dos gases gerados na carbonização resulta na redução de $97 \%$ da emissão de metano, $93 \%$ de monóxido de carbono e $95 \%$ da quantidade de material particulado (CARDOSO et al., 2010), refletindo em melhores condições ambientais e de trabalho.

Comparando os sistemas com e sem condução de brotação, foi visto que para o sistema fornosfornalha os indicadores econômicos VPL e VAE tiveram incremento de 65,6\% e o B/C foi incrementado em $16 \%$, em relação ao Cenário 1. A Lucratividade, passando do Cenário 1 para o Cenário 2, também teve aumento de 65,6\%. Em relação aos fornos "rabo-quente", o VPL e o VAE aumentaram em cerca de 14 vezes, o B/C passou de 1,01 para 1,18 (16,8\% de aumento) e a Lucratividade, de 1,1\% no Cenário 1 , alcançou $15,0 \%$ no Cenário 2, elevando-se cerca de 14 vezes.

Mesmo com grande desvantagem econômica frente a outras tecnologias, os sistemas de fornos "rabo-quente" são amplamente utilizados no Brasil. No país, $60 \%$ dos fornos utilizados são desse tipo (BRITO, 2010). Os sistemas, apesar de apresentarem baixa lucratividade, são economicamente viáveis, como provam os resultados das tabelas 3 e 6 . Dessa forma, um aumento na escala da praça de carbonização aumenta também o retorno financeiro de um empreendimento com esse tipo de forno. Outro fator que favorece o uso dessa tecnologia de conversão é a facilidade de construção e operação dos fornos.

Segundo Minette et al. (2007), um único trabalhador pode operar de sete a dez fornos, realizando as atividades de carregamento, controle da carbonização, descarga, deposição na praça e limpeza da área. Também é ponto positivo o fato de o investimento inicial para construção desses fornos normalmente ser mais baixo, sendo mais baratos do que os fornos de superfície, por exemplo, podendo propiciar um tempo mais curto de retorno do capital (DALLASTRA, 2010). O preço da madeira também tem forte influência no saldo anual desses projetos, como foi visto na tabela 5. Caso o produtor obtenha madeira a baixo custo, a atratividade do empreendimento é significativamente maior.

Segundo Colombo et al. (2006), ainda que existam situações econômicas que justifiquem o uso dos fornos "rabo-quente", a prática desse tipo de conversão da madeira vem atrelada a problemas de ordem ambiental e, algumas vezes, trabalhista. Num ambiente de crescente pressão da sociedade na 
direção da legalização, esse tipo de operação tende a ser substituída por outra mais eficiente do ponto de vista ecológico, social e econômico.

Nesse sentido, a exemplo do sistema fornos-fornalha, os fornos que contêm modernizações, como chaminés, câmaras de admissão de ar, fornalhas para queima da fumaça e meios de monitoramento da temperatura, têm benefícios no rendimento, na qualidade do carvão e no quesito ambiental, como explica Oliveira (2009). O autor comenta, por exemplo, que, com o monitoramento das temperaturas, é possível corrigir irregularidades térmicas durante a carbonização e definir o momento correto de abertura dos fornos, proporcionando redução no tempo de produção. Trugilho e Silva (2001) reforçam a importância desse tipo de modernização, concluindo que a temperatura final da carbonização é determinante na qualidade do carvão vegetal.

\section{CONCLUSÕES}

- Conclui-se que, nas condições apresentadas, a produção de carvão vegetal em ambos os sistemas produtivos, sistema fornos-fornalha e fornos "rabo-quente" foram viáveis economicamente.

- O sistema fornos-fornalha apresentou maior viabilidade econômica que os fornos "rabo-quente" nos dois cenários apresentados, ou seja, gerou maior lucro ao produtor de carvão vegetal.

- Ao conduzir a brotação, após a realização do corte da madeira de eucalipto, os custos com a condução da floresta são reduzidos, refletindo no menor custo da madeira. Assim, os indicadores econômicos e financeiros da produção de carvão vegetal elevam-se, ou seja, os projetos tornam-se mais viáveis economicamente.

\section{AGRADECIMENTOS}

Os autores agradecem ao Conselho Nacional de Desenvolvimento Científico e Tecnológico (CNPq), à Fundação de Amparo à Pesquisa de Minas Gerais (FAPEMIG), à Secretaria de Estado e Ciência, Tecnologia e Ensino Superior (SECTES), à Confederação da Agricultura e Pecuária do Brasil (CNA), ao Polo de Excelência em Florestas e à Associação das Siderúrgicas para Fomento Florestal (ASIFLOR).

\section{REFERÊNCIAS}

ARRUDA, T. P. M.; PIMENTA, A. S.; VITAL, B. R.; LUCIA, R. M. D.; ACOSTA, F. C. Avaliação de duas rotinas de carbonização em fornos retangulares. Revista Árvore, Viçosa, MG, v. 35, n. 4, p. 949 955,2011

BRITO, J. O. Desafios e perspectivas da produção e comercialização do carvão vegetal. 2010. II Fórum Nacional Sobre Carvão Vegetal. Sete Lagoas, MG. 2010.

CARDOSO, M. T.; DAMÁSIO, R. A. P.; CARNEIRO, A. C. O.; JACOVINE, L. A. G.; VITAL, B. R.; BARCELLOS, D. C. Construção de um sistema de queima de gases da carbonização para redução da emissão de poluentes. Cerne, Lavras, v. 16, Suplemento, p. 115 - 124, 2010.

CASTRO, R. R.; SILVA, M. L.; LEITE, H. G.; OLIVEIRA, M. L. R. Rentabilidade econômica e risco na produção de carvão vegetal. Cerne, Lavras, v. 13, n. 4, p. 353 - 359, 2007.

CENTRO DE INTELIGÊNCIA EM FlORESTAS (CIFLORESTAS). 2013. Preço de produtos Carvão vegetal. Viçosa, MG. Disponível em: 〈http://www.ciflorestas.com.br〉. Acesso em: 20/04/2013.

COLOMBO, S. de F. de O.; HATAKEYAMA, H.; PILATTI, L. A. O custo de produção como fator determinante do futuro da produção artesanal de carvão vegetal no Brasil. In: SIMPÓSIO DE ENGENHARIA DE PRODUÇÃO, 13., 2006, Bauru. Anais... Bauru: UNESP, 2006.

DALLASTRA, E. C. Sistemas de produção de carvão vegetal existentes no Brasil: uma análise de viabilidade econômica. 2010. 70 f. Dissertação (Mestrado em Agroenergia) - Fundação Getúlio Vargas, São Paulo, 2010. 
EMPRESA DE PESQUISA ENERGÉTICA (EPE). 2011. Balanço Energético Nacional 2011: Ano Base 2010. Rio de Janeiro, 2011. 266 p.

GUIMARÃES NETO, R. M.; PIMENTA, A. S.; SILVA, M. L.; SOARES, N. S.; VITAL, B. R.; SILVA, J. C. Avaliação econômica e financeira de projetos de fornos dos tipos container industrial e retangular de 40 estéreos. Revista Árvore, Viçosa, MG, v. 31, n. 4, p. 709 - 715, 2007.

MINETTE, L. J.; PIMENTA, A. S.; FARIA, M. M.; SOUZA, A. P.; SILVIA, E. P.; FIEDLER, N. C. Avaliação da carga de trabalho físico e análise biomecânica de trabalhadores da carbonização em fornos tipo "rabo-quente". 2007. Revista Árvore, Viçosa, MG, v. 31, n. 5, p. 853 - 858, 2007.

OLIVEIRA, A. C. Sistema forno-fornalha para produção de carvão vegetal. 2012. 73 f. Dissertação (Mestrado em Ciência Florestal) - Universidade Federal de Viçosa, Viçosa, MG, 2012.

OLIVEIRA, A. C.; CARNEIRO, A. C. O.; PEREIRA, B. L. C.; VITAL, B. R.; CARVALHO, A. M. M. L.; TRUGILHO, P. F.; DAMÁSIO, R. A. P. Otimização da produção do carvão vegetal por meio do controle de temperaturas de carbonização. Revista Árvore, Viçosa, MG, v. 37, n. 3, p. 557 - 566, 2013.

OLIVEIRA, R. L. M. de. Instrumentação e análise térmica do processo de produção de carvão vegetal. 2009. 129 f. Dissertação (Mestrado em Engenharia Mecânica) - Universidade Federal de Uberlândia, Uberlândia, 2009.

REZENDE, J. L. P.; OLIVEIRA, A. D. Análise econômica e social de projetos florestais. 2. ed. Viçosa: UFV, 2008, $386 \mathrm{p}$.

TRUGILHO, P. F.; SILVA, D. A. Influência da temperatura final de carbonização nas características físicas e químicas do carvão vegetal de jatobá (Himenea courbaril L.). Scientia Agraria, v. 2, n. 1-2, p. $45-53,2001$. 